\title{
A Two-Stage Hybrid Optimization Approach to Improve Transmission System Performance using FACTS Controllers under Open Access Environment
}

\author{
Sai Ram Inkollu ${ }^{1 *}$ and Venkata Reddy Kota ${ }^{2}$ \\ ${ }^{1}$ Department of Electrical, Dhanekula Institute of Engineering \& Technology, \\ Vijayawada - 521 139, Andhra Pradesh, India \\ ${ }^{2}$ Department of Electrical, Jawaharlal Nehru Technological University, \\ Kakinada - 533 003, Andhra Pradesh, India \\ Iinkollusiaram@gmail.com, ${ }^{2}$ kvr.jntu@gmail.com
}

\begin{abstract}
The Flexible AC Transmission System (FACTS) controllers have been resolved many technical issues which emerged with deregulated environment. One of such issues is transmission system performance improvement under open access. In this paper, two FACTS controllers, Thyristor-Switched Series Capacitor (TSSC) and Unified Power Flow Controller (UPFC) are selected to improve the system performance. At the first stage, the generation schedule under competitive electricity market dispatch model is obtained and at the second stage, the impact of the selected FACTS controllers is analyzed while executing various power transactions. A two-stage hybrid optimization approach using Gravitational Search Algorithm (GSA) and Particle Swarm Optimization (PSO) algorithm is adopted to find out the optimal location and parameters of FACTS controller to achieve the required objectives like voltage stability index maximization as well as transmission loss minimization. For case studies, standard IEEE 30 bus test system is used and the simulation results obtained have been validating for real-time adaptability of this proposed method.
\end{abstract}

Keywords: Deregulated power system, FACTS controllers, GSA-PSO, open access

\section{Introduction}

An ideal power system is generally partitioned as pools, utilities, and control areas and coordinating councils [1]. Generation, Transmission and distribution are the normal activities of single utility. It should supply electrical energy to all the consumers with sufficient generation to justify the load end with export/import commitment at expected reliability. Single utility maintains nominal spinning reserve and decide the cost which is to be assigned to the consumers that includes this reserve along with the generation, transmission and distribution expenses [2]. The natural monopolistic behavior of the traditional power system in all its utility functions such as generation, transmission, distribution and marketing results in non-competitive nature. This makes the system most unreliable, poor services on consumer's end and also owners of these utility functions decide energy prices on their own which may uneconomical. To encounter these problems, the solution suggested by the economists leads to development of deregulation structure of the traditional power system. In deregulation, the electricity industry could reform as either Vertically Integrated Utility (VIU) structure or Horizontally Integrated Utility (VIU) structure. Because of this type of orientation the system might be highly regulated and made drastic changes in monopolistic utilities by making the generation, transmission and distribution facilities as unbundled. This evolution has resulted to allow electric sector in to a competitive industry which has been driven by the market forces. 
Because of this, the competition has been increased among generators so that they can supply electrical energy to consumers at lower prices with high quality and security [3]. With the limited flexibility with traditional power flow controlling devices demands either expansion or up-gradation of the existing transmission system under this new scenario. Due to practical limitations, up-gradation has become one of the best solutions instead of expansion and that's why many networks have being equipped with flexible ac transmission system (FACTS) devices across the world from 1990s. The FACTS devices control the power flow in the line by supplying or absorbing reactive power, controlling the phase angle or series impedance and increasing or decreasing bus voltages [4]. Depends upon control attributes, the FACTS devices classified such as series compensators, shunt compensators and series-shunt/combined compensators. The series compensators like Static Synchronous Series Compensator (SSSC), Thyristor-Switched Series Capacitor (TSSC), Thyristor-Controlled Series Capacitor (TCSC), ThyristorControlled Voltage and Phase Angle Regulators (TCVRs and TCPARs), the shunt compensators like Static Var Compensators SVC and STATCOM and combined compensators like Unified Power Flow Controller (UPFC) and Interline Power Flow Controller (IPFC) etc., can be found in literature.

The best location of FACTS devices is one of the current research objectives. In order to meet high security margin, the location should satisfy certain prerequisites for satisfactory operation of the system. In general, the system stability, network loadability, transmission losses and power quality issues are some of the considerable objectives for optimization problem of FACTS devices. The best choice of FACTS devices and their optimal location is not a simple optimization problem due to their distinguished advantages and disadvantages of each device. So, the solution is mainly dependent on the concerned objective function. Specifically, the static modeling is used in heuristic optimization techniques application to find the optimal location of FACTS devices. This type of works concentrating on minimization of losses [5], voltage profile improvement [6], voltage stability enhancement [7], loadability enhancement [8], congestion management [9], Available Transfer Capability (ATC)/ Total Transfer Capability (TTC) enhancement [10-11] etc.

In this paper, the generation schedule is obtained for base case load under single-sided auction mechanism in competitive electricity market environment. Under open access, the bilateral or multilateral transactions are executed with an assumption of unconstrained transmission system. With this new generation and loading levels, the ability of various FACTS devices to improve transmission system performance is analyzed. The TCSC, TCPAR, UPFC and IPFC devices are used in this work. In order to identify the most suitable locations, the Gravitational Search Algorithm (GSA) [12] is applied and later, the Particle Swarm Optimization (PSO) [13] is implemented to optimize the parameters of FACTS devices. The overall voltage deviation index (VDI) is considered while optimizing the location and the transmission loss is considered while optimizing the parameters of FACTS devices.

The paper is arranged as follows: Section 1 gives introduction, the mathematical model for competitive electricity market driven schedule is explained in Section 2. The static power injection modeling of various FACTS devices are explained in Section 3. The objective function in terms of mathematical modeling is shown in Section 4. The hybrid algorithm approach is explained in Section 5. Later various case studies on standard IEEE test systems are explained in Section 6 and the conclusions are followed in Section 7.

\section{Deregulated Power System}

In deregulated power system [14], the generation companies (GENCOs) and distribution companies (DISCOs) will submit their offer prices and required demand to the system operator in sealed quotations. After receiving the various offers, the 
Independent System Operator (ISO) will do exercise to allocate generation and load levels to market participants. As single-sided auction mechanism is adopted in this work where the GENCOs only will participate in the auction. The dispatchable load in MW which is not constrained by congestion is termed as market clearing quantity (MCQ) and the corresponding price is termed as Market Clearing Price (MCP) in $\$ / M W h$. As per economic dispatch problem, the MCQ is treated as equivalent system demand (MW) which needs to allocate for various generators according to their cost coefficients under perfect competitive electricity market environment [15]. The total active power cost is computed as follows:

$$
\begin{gathered}
C_{t}(M C Q)=\sum_{i=1}^{N G} C_{t, i}\left(P_{g, i}\right) \\
C_{t, i}\left(P_{g, i}\right)=a_{i} P_{g, i}^{2}+b_{i} P_{g, i}+c_{i}
\end{gathered}
$$

The Market Clearing Price (MCP) in Rs/MWhr and schedule at a particular bus $i$, $M C Q_{i}$ in $\mathrm{MW}$ are determined as follows:

$$
\begin{gathered}
M C P=\frac{M C Q+\sum_{i=1}^{N G} \frac{b_{i}}{2 a_{i}}}{\sum_{i=1}^{N G} \frac{1}{2 a_{i}}} \\
M C Q_{i}=\frac{M C P-b_{i}}{2 a_{i}}
\end{gathered}
$$

By considering the effect of generator limits

$$
P_{g, i}^{\min } \leq M C Q_{i} \leq P_{g, i}^{\max }
$$

If a particular generator loading $P_{g, i}$ reaches the limit $P_{g, i}^{\min }$ or $P_{g, i}^{\max }$, its loading is held fixed at this value and the balance load is shared between the remaining generators on an equal incremental cost basis.

\subsection{Open Access Transmission}

According to Energy Policy Act of 1992 (EPAct) [16], the participants can use transmission system to access market opportunities beyond the nearest utilities. Under this environment, the power transactions can take place between various market participants irrespective of distance geographically. The power transactions among various participants can cause to alter total transmission losses significantly. In general, the transactions can be either bilateral or multilateral. Under bilateral transactions, the transaction can take place between any one power producer/source and one power consumer/sink where as under multilateral, we can have either one source with many sinks or many sources with one sink points as shown in Figure 1(a) and 1(b) respectively.

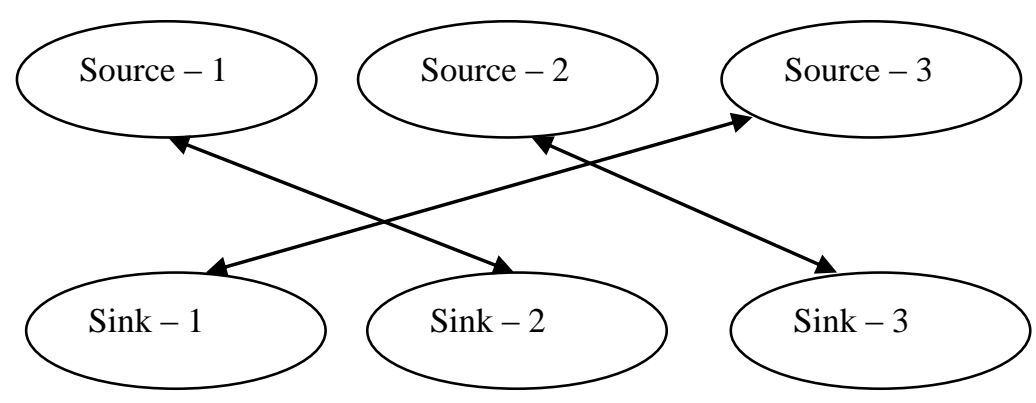

Figure 1(a). Illustration of Bilateral Transactions 


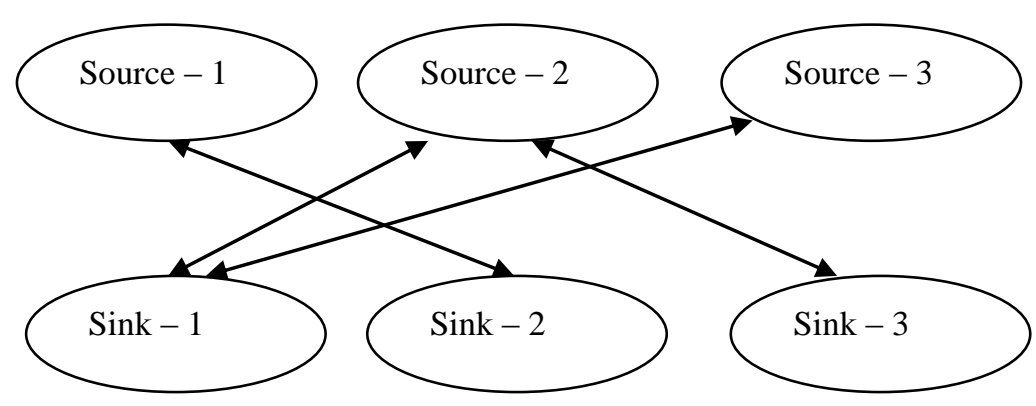

Figure 1(b).Illustration of Multilateral Transactions

All these transactions can take place only when transmission system supports. The management of transmission system security is the responsibility of system operator. Under inevitable case, he can curtail or reject some transactions as per norms of the market. In this work, we have assumed that the transmission system has sufficient security margin in terms of Available Transfer Capability (ATC) and aimed at only improvement of system voltage profile and loss minimization using any FACTS controller.

\section{Modeling of FACTS Devices}

\subsection{Mathematical Model of UPFC}

The power flow model of UPFC [17] is represented by mathematical equations as follows:

$$
\begin{gathered}
P_{i, i n j, u p f c}=0.02 r b_{i n} V_{i}^{2} \sin \gamma-1.02 r b_{i n} V_{i} V_{j} \sin \left(\theta_{i}-\theta_{j}+\gamma\right) \\
P_{j, i n j, u p f c}=r b_{i n} V_{i} V_{j} \sin \left(\theta_{i}-\theta_{j}+\gamma\right) \\
Q_{i, i n j, u p f c}=-r b_{i n} V_{i}^{2} \cos \gamma \\
Q_{j, i n j, u p f c}=r b_{i n} V_{i} V_{j} \cos \left(\theta_{i}-\theta_{j}+\gamma\right)
\end{gathered}
$$

where $V_{i}$ and $V_{j}$ are the magnitude and $\theta_{i}$ and $\theta_{j}$ are the angles of $i, j$ buses respectively and $b_{i n}$ is the series branch admittance.

\subsection{TCSC Mathematical Model}

The modeling of TCSC is given as [18]

$$
\begin{gathered}
P_{i n j, i}=-V_{i} V_{j}\left(\frac{1}{x_{i j}}\right) \sin \left(\delta_{i}-\delta_{j}\right) \\
Q_{i n j, i}=-V_{i}^{2}\left(\frac{1}{x_{i j}}\right)-V_{i} V_{j}\left(\frac{1}{x_{i j}}\right) \cos \left(\delta_{i}-\delta_{j}\right) \\
P_{i n j, j}=-P_{i n j, i} \\
Q_{i n j, i}=-V_{j}^{2}\left(\frac{1}{x_{i j}}\right)-V_{i} V_{j}\left(\frac{1}{x_{i j}}\right) \cos \left(\delta_{i}-\delta_{j}\right)
\end{gathered}
$$

where, $V_{i}$ and $V_{j}$ are the magnitude bus voltages at buses $i, j$ respectively, $\delta_{i}$ and $\delta_{j}$ are the load angles of buses $i, j$ respectively and $x_{i j}$ is the line reactance. 


\section{Problem Formulation}

The objective functions of the transmission system performance improvement problem contain two important terms: voltage deviation of the system, $f_{1}(x, u)$, and transmission losses, $f_{2}(x, u)$. The major objective function can be defined as:

$$
F(x, u)=\left[f_{1}(x, u), f_{2}(x, u)\right]
$$

The first objective is to optimize the overall system voltage profile i.e., minimize the voltage deviation at load buses, which can be defined as

$$
f_{1}(x, u)=V D I(x, u)=\sum_{i=1}^{N L B}\left|V_{i}-V_{i}^{r e f}\right|^{2}
$$

where $N B L$ is the number of load buses, $V_{i}^{\text {ref }}$ is the pre-specified reference value of the voltage magnitude at $\mathrm{i}^{\text {th }}$ load bus, and it is usually set at the value of 1.0 p.u.

The second objective is to minimize the total real power loss in the transmission lines, which is expressed as:

$$
f_{2}(x, u)=P_{l o s s}(x, u)=\sum_{i=1}^{N L} P_{i, l o s s}
$$

where $P_{i, \text { loss }}$ is the real power loss in transmission line $i$, and $N L$ is the total number of transmission lines.

In both the objective functions, $\boldsymbol{x}$ is the vector of dependent variables such as slack bus power $P_{G l}$, generator reactive power outputs $Q_{G}$, load bus voltages $V_{L}$ and apparent power flows in transmission lines $S_{L} \cdot \boldsymbol{x}$ can be define as:

$$
x^{T}=\left[P_{G 1}, Q_{G 1}, \ldots Q_{N G B}, V_{L 1}, \ldots V_{N L B}, S_{L 1}, \ldots S_{N L}\right]
$$

where $N G B$ is the number of generator buses.

Similarly, $\boldsymbol{u}$ is the vector of control variables such as generator bus voltages $V_{G}$, location of FACTS devices $L$, and real and reactive power injections $P_{i n j} \& Q_{i n j}$ at FACTS device incident buses $i, j$ respectively. $\boldsymbol{x}$ can be expressed as:

$$
u^{T}=\left[V_{G 1}, \ldots V_{N G B}, L_{1}, \ldots L_{N L}, P_{i n j, i}, Q_{i n j, i}, P_{i n j, j}, Q_{i n j, j}\right]
$$

As per the type of FACTS device, the power injections again controlled with their respective controlling parameters. The equality and inequality constraints involved in the mathematical model are as follows:

\section{a) Equality constraints}

Power flow equations corresponding to both real and reactive power balance equations are the equality constraints that can be written, for all the buses except buses $p$ and $q$ in which UPFC is connected, as

$$
\begin{gathered}
P_{i}=P_{g, i}-P_{d, i}=\sum_{k=1}^{N B}\left|V_{i}\right|\left|V_{k}\right|\left|Y_{i k}\right| \cos \left(\theta_{i k}-\delta_{i}+\delta_{j}\right) \\
Q_{i}=Q_{g, i}-Q_{d, i}=-\sum_{k=1}^{N B}\left|V_{i}\right|\left|V_{k}\right|\left|Y_{i k}\right| \sin \left(\theta_{i k}-\delta_{i}+\delta_{j}\right), i=1,2, \ldots, N B ; \text { but } i \neq p, q
\end{gathered}
$$

For buses $p$ and $q$, the quality constraints can be written as

$$
\begin{gathered}
P_{p}=P_{g, p}-P_{d, p}=\sum_{k=1}^{N B}\left|V_{p}\right|\left|V_{k}\right|\left|Y_{p k}\right| \cos \left(\theta_{p k}-\delta_{p}+\delta_{j}\right)-P_{p, i n j} \\
Q_{p}=Q_{g, p}-Q_{d, p}=-\sum_{k=1}^{N B}\left|V_{p}\right|\left|V_{k}\right|\left|Y_{p k}\right| \sin \left(\theta_{p k}-\delta_{p}+\delta_{j}\right)-Q_{p, i n j} \\
P_{q}=P_{g, q}-P_{d, q}=\sum_{k=1}^{N B}\left|V_{q}\right|\left|V_{k}\right|\left|Y_{q k}\right| \cos \left(\theta_{q k}-\delta_{q}+\delta_{j}\right)+P_{q, i n j} \\
Q_{q}=Q_{g, q}-Q_{d, q}=-\sum_{k=1}^{N B}\left|V_{q}\right|\left|V_{k}\right|\left|Y_{q k}\right| \sin \left(\theta_{q k}-\delta_{q}+\delta_{j}\right)+Q_{q, i n j}
\end{gathered}
$$




\section{b) Inequality constraints}

- Real power generation limits: This includes the upper and lower real power limit of generators.

$$
P_{g, i}^{\min } \leq P_{g, i} \leq P_{g, i}^{\max }, \quad i=1,2, \ldots, N G
$$

- $\quad$ Reactive power generation limits: This includes the upper and lower reactive power limit of generators.

$$
Q_{g, i}^{\min } \leq Q_{g, i} \leq Q_{g, i}^{\max }, \quad i=1,2, \ldots, N G
$$

- Voltage limits: This includes the upper and lower limits on the bus voltage magnitude.

$$
\left|V_{i}^{\min }\right| \leq\left|V_{i}\right| \leq\left|V_{i}^{\max }\right|, \quad i=1,2, \ldots, N B
$$

- $\quad$ Phase angle limits: This includes the upper and lower limits on the bus voltage phase angle.

$$
\delta_{i}^{\min } \leq \delta_{i} \leq \delta_{i}^{\max }, \quad i=1,2, \ldots, N B
$$

- Tap-Changers limits: This includes the upper and lower limits on the tap positions in tap-changing transformer lines.

$$
a_{i}^{\min } \leq a_{i} \leq a_{i}^{\max }, \quad i=1,2, \ldots, N T C L
$$

- MVAr injection limits: This includes the upper and lower limits on the MVAr injections at voltage controlled buses.

$$
Q_{i n j, i}^{\min } \leq Q_{i n j, i} \leq Q_{i j j, i}^{\max }, \quad i=1,2, \ldots, N V C B
$$

- Line flow limits: These constraints represent the maximum MVA power flow in a transmission line.

$$
\left|S_{l}\right| \leq\left|S_{l}^{\max }\right|, \quad l=1,2, \ldots, N L
$$

\section{Hybrid Approach (PSO-GSA)}

The hybrid algorithm adopted here is similar to our previous works and the detailed algorithm can be found [19]. The pseudo code of the procedure involved in PSO-GSA is as follows:

\begin{tabular}{|l|l|}
\hline GSA & PSO \\
\hline 1. Search space identification, $\mathrm{t}=0 ;$ & 1. For each particle \\
2. Random initialization, $X i(t) ;$ & Initialize particle, End \\
For $i=1, \ldots, N$ & Do \\
3. Fitness evaluation of objects; & 2. For each particle \\
4. Update the parameters of $G$, best, worst & Calculate fitness value \\
and $M ;$ & If the fitness value is better than the best \\
For $i=1, \ldots, N$ & fitness value $(p B e s t)$ in history \\
5. Calculation of the force on each object; & iii. Set current value as the new pBest \\
6. Calculation of the acceleration and the & End \\
velocity of each object; & 3. Choose the particle with the best fitness \\
7. Update the position of the agents by (4) & value of all the particles as the $g B e s t$ \\
to yield $X i(t+1) ;$ & 4. For each particle \\
$\mathrm{t}=\mathrm{t}+1 ;$ & Calculate particle velocity \\
8. Repeat steps 3 to 7 until the stop criteria & Update particle position \\
is reached; & End - while maximum iterations or \\
9. End & minimum error criteria is not attained. \\
& \\
\hline
\end{tabular}




\section{Simulation Results \& Discussions}

In order to verify its feasibility, the PSO-GSA algorithm is applied to optimal placement of each FACTS device on the IEEE 30-bus test system. The test system consists of 6 generator buses, 21 load buses, 41 transmission lines. The real load of the system is $283.4 \mathrm{MW}$ and is equal to market clearing quantity. The generator cost coefficients are given in Table -1. By performing market clearing mechanism, the schedule is given in Table 2. The market clearing price is $38.88 \$ / \mathrm{MWh}$ and corresponding operating cost is $8343.40 \$ / \mathrm{h}$.

Table 1. Generators Cost Coefficients

\begin{tabular}{|c|c|c|c|c|c|}
\hline Gen. bus no & a & b & C & Pmin & Pmax \\
\hline 1 & 0.038432 & 20 & 0 & 0 & 360.2 \\
\hline 2 & 0.25 & 20 & 0 & 0 & 140 \\
\hline 5 & 0.01 & 40 & 0 & 0 & 100 \\
\hline 8 & 0.01 & 40 & 0 & 0 & 100 \\
\hline 11 & 0.01 & 40 & 0 & 0 & 100 \\
\hline 13 & 0.01 & 40 & 0 & 0 & 100 \\
\hline
\end{tabular}

Table 2. Market Driven Schedule

\begin{tabular}{|c|c|c|c|c|c|c|c|}
\hline \multicolumn{6}{|c|}{ Real power generation in MW } & \multirow{2}{*}{$\begin{array}{c}\mathrm{MCP} \\
(\$ / \mathrm{MWh})\end{array}$} & \multirow{2}{*}{$\begin{array}{l}\text { Operating } \\
\text { Cost }(\$ / h)\end{array}$} \\
\hline G1 & $\mathrm{G} 2$ & G3 & G4 & G5 & G6 & & \\
\hline 245.6385 & 37.7615 & 0 & 0 & 0 & 0 & 38.880 & 8343.40 \\
\hline
\end{tabular}

Since the test system has consisting of 6 generator buses and 21 load buses. Hence each generator can treat as source bus and similarly each load bus can be like a sink bus. By observing market schedule, generators 3, 4, 5, and 6 are not allocated any schedule due to their high pricing quotation. They can participant either in open access market or reserve market. Similarly, even generators 1 and 2 has some reserve power, they can also participant in any other markets. The following bilateral contracts are executed in the open access market. Since the participants and their required MW quantities are unpredictable in real-time, we have determined by using random numbers theory. It means, the algorithm will decide the source bus and sink bus as well as their contracted power. For each simulation, we can have one bilateral contract and hence numerous case studies can generate. Here we have given some limited transactions in Table 3.

\subsection{Single Source - Single Sinks Simulation Results}

The base case transmission loss before transaction is 18.0524 MW. It has been increased during tractions and the TCSC controls in line 12-16 are minimized that increased loss at every transaction. Similarly, the voltage deviation index (VDI) is high without TCSC and it is also decreased with TCSC. Finally, the transmission losses as well as VDI are optimized at every bilateral transaction as given in Table 3. The voltage profile as well as transmission loss in each transmission line are illustrated in Figure 2 and Figure 3 respectively. 
Table 3. TCSC Impact on Losses and VDI for Single Source - Single Sink Transactions

\begin{tabular}{|c|c|c|c|c|c|c|c|}
\hline \multirow{2}{*}{ Source } & \multirow{2}{*}{ Sink } & \multirow{2}{*}{\begin{tabular}{c} 
Contracted \\
Power \\
\cline { 4 - 8 }
\end{tabular}} & & \multicolumn{2}{|c|}{ Transmission losses (MW) } & \multicolumn{2}{c|}{ VDI } \\
\cline { 5 - 8 } & & $\begin{array}{c}\text { Before } \\
\text { transaction }\end{array}$ & $\begin{array}{c}\text { After } \\
\text { transaction }\end{array}$ & $\begin{array}{c}\text { With } \\
\text { TCSC }\end{array}$ & $\begin{array}{c}\text { Without } \\
\text { TCSC }\end{array}$ & $\begin{array}{c}\text { With } \\
\text { TCSC }\end{array}$ \\
\hline 1 & 24 & 2.553 & 18.052 & 20.378 & 18.219 & 0.012 & 0.007 \\
\hline 5 & 8 & 3.849 & 18.052 & 19.983 & 18.311 & 0.011 & 0.008 \\
\hline 1 & 18 & 4.716 & 18.052 & 22.019 & 18.093 & 0.008 & 0.007 \\
\hline 2 & 16 & 3.356 & 18.052 & 18.577 & 18.176 & 0.009 & 0.007 \\
\hline 5 & 23 & 3.827 & 18.052 & 18.220 & 18.051 & 0.012 & 0.007 \\
\hline
\end{tabular}

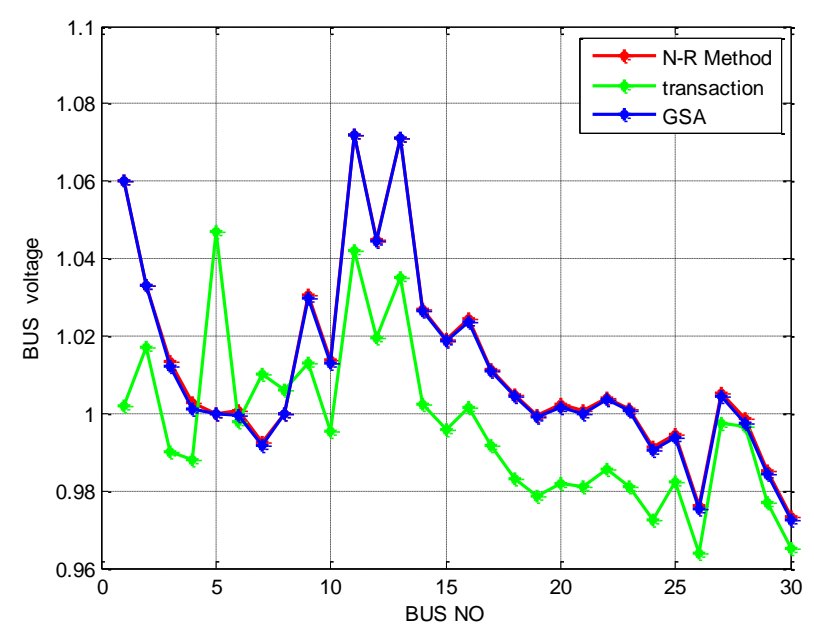

Figure 2. Voltage Profile at each Bus with TCSC

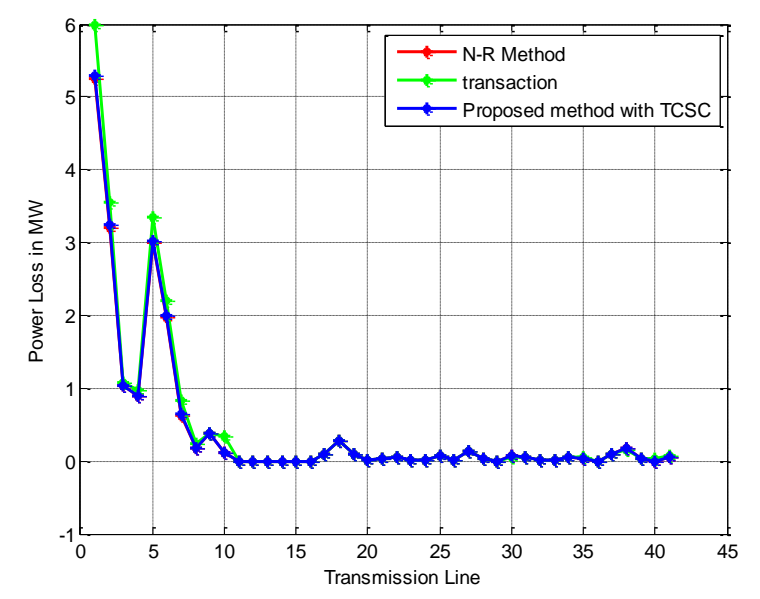

Figure 3. Loss in each Transmission Line

\subsection{Single Source - Multiple Sinks Simulation Results with TCSC}

In Section 6.1, we have executed only with one source bus and one sink bus. In this Section, one source bus and two sink buses are considered for each transaction. The combined increased load at two sink buses is supplied by one source bus. The multilateral contracts and system performance with TCSC are given in Table 4 and Table 5 respectively. 
For multiple sources - single sink transactions and corresponding TCSC impact on system performance are given in Table 6 and Table 7 respectively. Similarly, for multiple sources - multiple sinks and corresponding TCSC impact on system performance are given in Table 8 and Table 9 respectively.

Table 4. Multilateral Transactions for Single Source - Multiple Sinks

\begin{tabular}{|c|c|c|c|c|c|}
\hline \multirow{2}{*}{ Source } & \multirow{2}{*}{ Sinks } & \multicolumn{3}{|c|}{ Contracted Power (MW) } \\
\cline { 3 - 6 } & \multicolumn{2}{|c|}{} & At sink 1 & At sink 2 & Total \\
\hline 11 & 17 & 15 & 2.958 & 2.491 & 5.4490 \\
\hline 1 & 19 & 21 & 3.044 & 2.999 & 6.0430 \\
\hline 13 & 4 & 7 & 4.618 & 2.844 & 7.4620 \\
\hline 8 & 26 & 4 & 4.942 & 2.845 & 7.7870 \\
\hline 2 & 20 & 17 & 1.524 & 1.064 & 2.5880 \\
\hline
\end{tabular}

Table 5. TCSC Impact on Losses and VDI for Single Source - Multiple Sinks

\begin{tabular}{|c|c|c|c|c|}
\hline \multicolumn{2}{|c|}{ Transmission losses (MW) } & \multicolumn{2}{c|}{ VDI } \\
\hline $\begin{array}{c}\text { Before } \\
\text { transaction }\end{array}$ & $\begin{array}{c}\text { After } \\
\text { transaction }\end{array}$ & $\begin{array}{c}\text { With } \\
\text { TCSC }\end{array}$ & $\begin{array}{c}\text { Without } \\
\text { TCSC }\end{array}$ & $\begin{array}{c}\text { With } \\
\text { TCSC }\end{array}$ \\
\hline 18.0524 & 19.0700 & 18.1466 & 0.011935 & 0.007197 \\
\hline 18.0524 & 21.6436 & 18.2011 & 0.011475 & 0.007268 \\
\hline 18.0524 & 18.9150 & 18.1158 & 0.013516 & 0.007897 \\
\hline 18.0524 & 20.0147 & 18.1781 & 0.014272 & 0.007169 \\
\hline 18.0524 & 20.9641 & 18.0898 & 0.020269 & 0.007908 \\
\hline
\end{tabular}

6.3. Multiple Sources - Single Sink Simulation Results with TCSC

Table 6. Multilateral Transactions for Multiple Sources - Single Sink

\begin{tabular}{|c|c|c|c|c|c|}
\hline \multicolumn{2}{|c|}{ Sources } & Sink & \multicolumn{3}{|c|}{ Contracted Power (MW) } \\
\cline { 4 - 6 } & & At source 1 & At source 2 & Total \\
\hline 2 & 1 & 23 & 1.183 & 3.051 & 4.2340 \\
\hline 13 & 11 & 16 & 1.560 & 4.961 & 4.9610 \\
\hline 1 & 8 & 14 & 2.205 & 4.928 & 7.1330 \\
\hline 1 & 13 & 8 & 3.044 & 1.665 & 4.8090 \\
\hline 8 & 11 & 30 & 3.295 & 4.487 & 7.7820 \\
\hline
\end{tabular}

Table 7. TCSC Impact on Losses and Voltage VDI for Multiple Sources Single Sink

\begin{tabular}{|c|c|c|c|c|}
\hline \multicolumn{2}{|c|}{ Transmission losses (MW) } & \multicolumn{2}{c|}{ VDI } \\
\hline $\begin{array}{c}\text { Before } \\
\text { transaction }\end{array}$ & $\begin{array}{c}\text { After } \\
\text { transaction }\end{array}$ & $\begin{array}{c}\text { With } \\
\text { TCSC }\end{array}$ & $\begin{array}{c}\text { Without } \\
\text { TCSC }\end{array}$ & $\begin{array}{c}\text { With } \\
\text { TCSC }\end{array}$ \\
\hline 18.0524 & 20.6991 & 18.2421 & 0.014148 & 0.0078848 \\
\hline 18.0524 & 20.3963 & 18.1041 & 0.012325 & 0.0079023 \\
\hline 18.0524 & 19.421 & 18.1825 & 0.016016 & 0.0072186 \\
\hline 18.0524 & 22.2499 & 18.1812 & 0.016109 & 0.0071545 \\
\hline
\end{tabular}




\begin{tabular}{|l|l|l|l|l|}
\hline 18.0524 & 19.0614 & 18.1887 & 0.012842 & 0.0078537 \\
\hline
\end{tabular}

6.4. Multiple Sources - Multiple Sinks Simulation Results with TCSC

Table 8. Multilateral Transactions for Multiple Sources - Multiple Sinks

\begin{tabular}{|c|c|c|c|c|c|c|c|c|}
\hline \multirow{2}{*}{$\begin{array}{c}\text { Source } \\
\text { s }\end{array}$} & \multicolumn{2}{|c|}{ Sinks } & \multicolumn{5}{|c|}{ Contracted Power (MW) } \\
\cline { 5 - 10 } & \multicolumn{2}{|c|}{$\begin{array}{c}\text { At } \\
\text { source 1 }\end{array}$} & $\begin{array}{c}\text { At } \\
\text { source 2 }\end{array}$ & At sink 1 & $\begin{array}{c}\text { At sink } \\
\mathbf{2}\end{array}$ & Total \\
\hline 2 & 11 & 8 & 15 & 1.1410 & 2.7040 & 1.1410 & 2.7040 & 3.8450 \\
\hline 13 & 5 & 23 & 14 & 1.3750 & 2.7510 & 1.3750 & 2.7510 & 4.1260 \\
\hline 1 & 11 & 18 & 12 & 2.7970 & 1.5630 & 2.7970 & 1.5630 & 4.3600 \\
\hline 13 & 2 & 8 & 17 & 4.3650 & 3.9080 & 4.3650 & 3.9080 & 8.2730 \\
\hline 1 & 5 & 8 & 26 & 4.7530 & 1.6910 & 4.7530 & 1.6910 & 6.4440 \\
\hline
\end{tabular}

Table 9. TCSC Impact on Losses and Voltage VDI for Multiple Sources Single Sink

\begin{tabular}{|c|c|c|c|c|}
\hline \multicolumn{2}{|c|}{ Transmission losses (MW) } & \multicolumn{2}{c|}{ VDI } \\
\hline $\begin{array}{c}\text { Before } \\
\text { transaction }\end{array}$ & $\begin{array}{c}\text { After } \\
\text { transaction }\end{array}$ & $\begin{array}{c}\text { With } \\
\text { TCSC }\end{array}$ & $\begin{array}{c}\text { Without } \\
\text { TCSC }\end{array}$ & $\begin{array}{c}\text { With } \\
\text { TCSC }\end{array}$ \\
\hline 18.0524 & 18.385 & 18.2514 & 0.022602 & 0.0072249 \\
\hline 18.0524 & 20.3159 & 18.2993 & 0.027708 & 0.00722 \\
\hline 18.0524 & 22.8488 & 18.3290 & 0.014674 & 0.0072985 \\
\hline 18.0524 & 19.0252 & 18.2218 & 0.010419 & 0.0084134 \\
\hline 18.0524 & 19.6042 & 18.6824 & 0.007678 & 0.0078779 \\
\hline
\end{tabular}

\subsection{Multiple Sources - Multiple Sinks Simulation Results with UPFC}

The base case transmission loss before transaction is 18.0524 MW. It has been increased during tractions and the UPFC controls in line 12-16 are minimized that increased loss at every transaction. Similarly, the voltage deviation index (VDI) is high without UPFC and it is also decreased with UPFC. Finally, the transmission losses as well as VDI are optimized at every multilateral transaction as given in Table 10 and Table 11 respectively. The voltage profile as well as transmission loss in each transmission line are illustrated in Figure 4 and Figure 5 respectively.

Table 10. Multilateral Transactions for Multiple Sources - Multiple Sinks

\begin{tabular}{|c|c|c|c|c|c|c|c|c|}
\hline \multicolumn{2}{|c|}{ Sources } & \multicolumn{2}{|c|}{ Sinks } & \multicolumn{5}{|c|}{ Contracted Power (MW) } \\
\cline { 5 - 10 } & & $\begin{array}{c}\text { At } \\
\text { source 1 }\end{array}$ & $\begin{array}{c}\text { At } \\
\text { source 2 }\end{array}$ & At sink 1 & At sink 2 & Total \\
\hline 13 & 2 & 12 & 4 & 2.5050 & 4.2690 & 2.5050 & 4.2690 & 6.7740 \\
\hline 5 & 8 & 4 & 29 & 3.9780 & 3.1220 & 3.9780 & 3.1220 & 7.1000 \\
\hline 2 & 1 & 23 & 23 & 2.5160 & 1.8890 & 2.5160 & 1.8890 & 4.4050 \\
\hline 1 & 1 & 4 & 14 & 4.9140 & 1.5790 & 4.9140 & 1.5790 & 6.4930 \\
\hline 11 & 1 & 7 & 30 & 3.3780 & 2.9850 & 3.3780 & 2.9850 & 6.3630 \\
\hline
\end{tabular}


Table 11. UPFC Impact on Losses and VDI for Multiple Sources - Multiple Sinks

\begin{tabular}{|c|c|c|c|c|}
\hline \multicolumn{2}{|c|}{ Transmission losses (MW) } & \multicolumn{2}{c|}{ VDI } \\
\hline $\begin{array}{c}\text { Before } \\
\text { transaction }\end{array}$ & $\begin{array}{c}\text { After } \\
\text { transaction }\end{array}$ & $\begin{array}{c}\text { With } \\
\text { TCSC }\end{array}$ & $\begin{array}{c}\text { Without } \\
\text { TCSC }\end{array}$ & $\begin{array}{c}\text { With } \\
\text { TCSC }\end{array}$ \\
\hline 18.0524 & 18.6925 & 16.9006 & 0.016705 & 0.0072563 \\
\hline 18.0524 & 19.7194 & 17.0432 & 0.038081 & 0.0073707 \\
\hline 18.0524 & 22.2093 & 17.4779 & 0.013885 & 0.0071599 \\
\hline 18.0524 & 18.5453 & 16.787 & 0.0069466 & 0.0072757 \\
\hline 18.0524 & 21.0251 & 17.0329 & 0.014991 & 0.0074026 \\
\hline
\end{tabular}

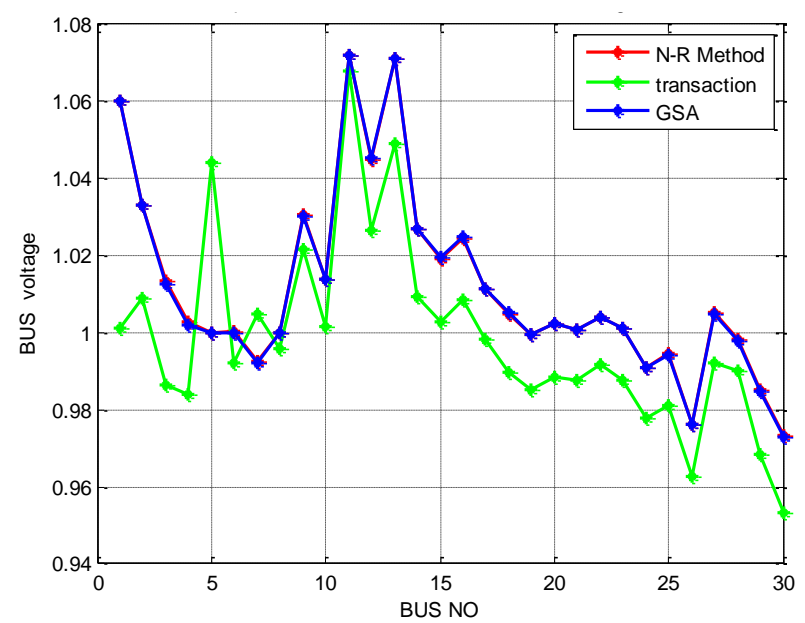

Figure 4. Bus Voltage Profile with UPFC

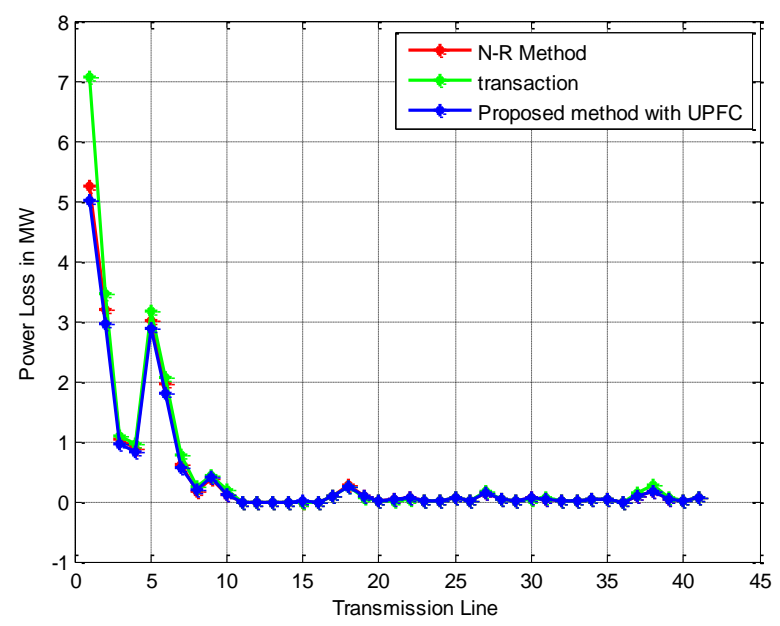

Figure 5. Loss in each Transmission Line with UPFC

\section{Conclusions}

In open access transmission system, the transactions can take place at any time among various market participants. Some transactions can cause to decrease total transmission losses due to counter flows and some are cause to increase due to dominant flows. Irrespective of transactions and their volumes, the major responsibility of power system engineers is to decrease net transmission losses as well as to maintain good voltage profile 
for the better performance of system. In this paper, the impact of TCSC and UPFC on the system performance is analyzed for both bilateral and multilateral transactions. It has been observed that the transmission losses are decreased and voltage profile is increased significantly with FACTS controllers in the network. The adopted method is proved its ability to solve complex optimization problem with multiple objectives.

\section{References}

[1] Lai, L. L. "Energy Generation under the New Environment, in Power System Restructuring and Deregulation: Trading, Performance and Information Technology (ed L. L. Lai)", John Wiley \& Sons, Ltd, Chichester, UK. doi: 10.1002/0470846119.ch1. (2001).

[2] William W. Hogan, "A Competitive Electricity Market Model, Center For Business And Government", John F. Kennedy School of Government, Harvard University, Cambridge, Massachusetts 02138 (1993)

[3] Paul L. Joskow, "Lessons Learned From Electricity Market Liberalization, The Energy Journal, Special Issue. The Future of Electricity: Papers in Honor of David Newbery, IAEE, (2008).

[4] N. G. Hingorani and L. Gyugyi, "Understanding FACTS: Concepts and Technology of Flexible AC Transmission System”, New York: IEEE Press, (2000).

[5] Tripathy, M., et al. "Transmission loss reduction based on FACTS and bacteria foraging algorithm." Parallel Problem Solving from Nature-PPSN IX. Springer Berlin Heidelberg, pp. 222-231, (2006)

[6] Baghaee, H. R., et al. "Improvement of voltage stability and reduce power system losses by optimal GAbased allocation of multi-type FACTS devices." IEEE 11th International Conference on Optimization of Electrical and Electronic Equipment, OPTIM 2008. (2008).

[7] Perez, M. A., A. R. Messina, and C. R. Fuerte-Esquivel. "Application of FACTS devices to improve steady state voltage stability." . IEEE Power Engineering Society Summer Meeting, 2000, vol. 2. (2000).

[8] Saravanan, M., et al. "Application of particle swarm optimization technique for optimal location of FACTS devices considering cost of installation and system loadability." Electric Power Systems Research, vol. 77, no. 3 (2007), pp. 276-283.

[9] Singh, S. N., and A. K. David. "Optimal location of FACTS devices for congestion management." Electric Power Systems Research, vol. 58, no.2, (2001), pp. 71-79.

[10] Xiao, Ying, et al. "Available transfer capability enhancement using FACTS devices." IEEE Transactions on Power systems, vol.18, no.1, (2003), pp.305-312.

[11] Verma, K. S., S. N. Singh, and H. O. Gupta. "FACTS devices location for enhancement of total transfer capability." 2001 IEEE Power Engineering Society Winter Meeting, vol. 2 (2001).

[12] Rashedi, Esmat, Hossein Nezamabadi-Pour, and Saeid Saryazdi. "GSA: a gravitational search algorithm." Information sciences, vol. 179, no. 13, (2009), pp. 2232-2248.

[13] Kennedy, James. "Particle swarm optimization." Encyclopedia of machine learning. Springer US, (2011), pp. 760-766.

[14] Woo, Chi-Keung, Debra Lloyd, and Asher Tishler. "Electricity market reform failures: UK, Norway, Alberta and California." Energy policy, vol. 31, no. 11, (2003), pp.1103-1115.

[15] J. Vara Prasad and K. Chandra Sekhar, "Assessment of Spinning Reserve under Strategic Bidding in a Competitive Energy System", IEEE International Conference on Energy Efficient Technologies for Sustainability (ICEETS'13), St. Xavier's Catholic College of Engineering, Chunkankadai, Nagercoil, Tamilnadu, India, (2013)

[16] Watkiss, Jeffrey D., and Douglas W. Smith. "The Energy Policy Act of 1992-A Watershed for Competition in the Wholesale Power Market, " Yale J. on Reg. 10 (1993): 447.

[17] Vural, A. Mete, and Mehmet Tümay. "Mathematical modeling and analysis of a unified power flow controller: A comparison of two approaches in power flow studies and effects of UPFC location." International Journal of Electrical Power \& Energy Systems, vol. 29, no.8, (2007), pp. 617-629.

[18] Ehsan, M., and S. M. T. Bathaee. "An efficient power injection modeling and sequential power flow algorithm for FACTS devices." IEEE SoutheastCon, 2004. Proceedings, (2004).

[19] Sai Ram Inkollu and Venkata Reddy Kota, "Optimal setting of FACTS devices for voltage stability improvement using PSO adaptive GSA hybrid algorithm," Engineering Science and Technology, an International Journal, Available online 17 March (2016). 